\title{
Relação do Poder Judiciário e Democracia no Pensamento de Calmon de Passos
}

\section{Relationship Between the Judiciary and Democracy in Accordance with the Thought of Calmon de Passos}

"O neoconstitucionalismo é uma ideologia antidemocrática e despolitizadora na medida em que propõe o direito como fonte de libertação e o Judiciário como agente de transformação.” J. J. Calmon de Passos

Beclaute Oliveira Silva'

${ }^{1}$ Universidade Fede'ral de Alagoas - UFAL, Brasil

\section{Resumo}

O presente artigo é a transcrição, com alguns ajustes, da palestra proferida pelo autor, no "Congresso Centenário de Calmon de Passos" promovido pela Associação Norte Nordeste de Professores de Processo (ANNEP) e analisa o modo como o homenageado percebe a relação entre o Poder Judiciário e a Democracia. A pesquisa tem por base análise bibliográfica. Constatouse, no desenvolver da exposição, que Calmon de Passos não vê diferenciação entre direito e poder e, por isso, o analisa como faces da mesma moeda. No entanto, percebe, na democracia, um processo apto a tornar esse poder uma manifestação legítima. Percebeu-se, também, que o Poder Judiciário é um importante agente da democracia quando atua de modo contra majoritário, preservando as minorias e a diferença que torna o poder uma estrutura não hegemônica.

Palavras-chave: Calmon de Passos; Direito; Poder; Democracia; Função contra majoritária; Poder judiciário

\section{Abstract}

This article is a dictation, with some adjustments, of the lecture performed by the author at the "Calmon de Passos Centennial Congress ", which was promoted by the North-Northeast Association of Procedure Teachers (ANNEP) and analyzes the way the honored one -- Calmon de Passos - remarks the relationship between the Judiciary and Democracy. The research is based on bibliographical analysis. It was found in the development of the exhibition that Calmon de Passos sees no differentiation between law and power and, therefore, he analyzes it as sides of the same coin. However,

he notices, in democracy, a process capable of making this power a legitimate manifestation. It has also been perceived that the Judiciary is an important agent of democracy when it acts against the majority, preserving minorities and the difference that makes power a non-hegemonic structure.

Keywords: Calmon de Passos; Law; Power; Democracy; Countermajoritarian Function; Judiciary Power

\section{Introdução}

O presente artigo é a transcrição, com alguns ajustes, de palestra proferida pelo autor, no “Congresso Centenário de Calmon de Passos”, organizado pela Associação Norte Nordeste de Professores de Processo (ANNEP), nos dias 09, 10 e 11 de julho de 2020, por meio virtual, atualmente hospedado no canal do Youtube da ANNEP. ${ }^{1}$

1 Transcrição da palestra veiculada no "Congresso Centenário de Calmon de Passos, em 11.7.2020. Acesso em 7 de agosto de 2020. Disponível em: https:/ / www.youtube.com/watch?v=Dg89aGndXcI 
O homenageado foi um importante estudioso do direito brasileiro. Ele elegeu o processo como o fio condutor de toda sua obra. Mas ele não trata o processo só pelo aspecto jurisdicional e sim como uma categoria apta a servir de modelo para as interações e formas de organização do poder.

Foi um ator influente quando em vida e, após sua morte, seus escritos e vídeos têm sido revisitados por quem deseja conhecer um pouco mais de nossa forma de lidar com esse fenômeno, o poder.

A exposição aqui proposta tomou por base um texto específico de Calmon de Passos, de publicação póstuma, denominado Revisitando o direito, o poder, a justiça e o processo. Ele será nosso ponto e partida e o farol para nossa eventual chegada. Através dele serão traçadas algumas interações que o pensamento de Calmon realizou durante sua formação cultura.

Aqui uma alerta. Calmon trafega por diversos ambientes. Muitos deles ásperos. É nítido no pensamento do homenageado que ele não tinha medo de intempéries, afinal, como já diz o dito popular, "mar calmo nunca fez bom marinheiro". Com maestria, ele singrava esses mares bravios. As tormentas que desbravava não deixava e nem deixa seu leitor tranquilo. Calmon sempre nos deixou inquieto. É essa inquietude que ele suscitava que o tornou um dos nossos grandes mestres. Como Sócrates, Calmon desperta em nós a inquietação e a admiração.

Para analisar esse modo de pensar do autor, será feita uma análise bibliográfica, buscando identificar as influências que permeiam seu pensamento. O método utilizado será o dedutivo, já que se pretende, a partir de uma obra identificar suas interações. O caminho escolhido é fundamental para que seja possível identificar o fio condutor que interliga o papel do Poder Judiciário e a democracia. As duas categorias são tratadas muitas vezes como categorias estanques, dissociadas. Pretende-se demonstrar que essa interligação é algo presente e necessário. Sua aparente dissociação é uma artimanha do poder que adora se esconder e assim atuar sem ser percebido.

O percurso a ser traçado seguirá, em primeiro lugar a descrição de como Calmon e sua forma de pensar chegou à vida intelectual do autor. Não se trata de mero relato, mas de um destaque que demonstra como o pensamento do homenageado interage em locais, tempos e modos diversos, produzindo resultados inesperados.

Depois, será demonstrado como o direito interage com o poder. Essa relação tem sido negligenciada nas academias, inclusive. Para Calmon, trata-se da pedra angular para compreender o modo como os sistemas jurídicos se estruturam.

Por fim, e não poderia ser diferente, a crítica contundente ultimada pelo homenageado ao neoconstitucionalismo e de como ele contribui para a construção de um direito autoritário e pouco democrático.

Todo o trabalho terá por ponto central a análise da democracia. Ela é a categoria que garante um exercício de poder controlado e legítimo.

\section{Calmon de Passos em minha formação}

Calmon de Passos chega à minha vida de forma muito interessante, logo quando cheguei a Maceió. Eu sou de Alagoas, mas sou do interior: de Penedo. Havia passado no vestibular e iria fazer o curso de direito na Ufal, em 1990.

As aulas teriam início em agosto, mas houve uma greve e elas só começaram em setembro. Eu já estava acostumado com as greves, pois era oriundo de escola pública e lá a greve era algo comum. Aqui, só um registro. Sou de escola pública desde a alfabetização até o doutorado, fato que me dá muito orgulho. Na primeira quarta-feira de setembro, lembro muito bem, tive aula com o professor Nabor Bulhões, um grande mestre, um jurista fantástico, advogado brilhante, à época, presidente da OAB em Alagoas. Naquela aula, ele falou sobre a conferência que teve da OAB poucos dias antes e, no evento, havia saído uma moção de repúdio contra o Tribunal de Justiça da Bahia pela perseguição ao professor e advogado Calmon de Passos. Foi então a primeira vez que ouvi falar de Calmon de Passos. Relatava o estimado professor que a perseguição era tão grande que tudo que ele ajuizasse era indeferido. 
Começar a faculdade tomando conhecimento da luta do aguerrido advogado e professor marcou desde o início minha formação. Confesso que me perguntava como o Judiciário poderia perseguir uma pessoa que, segundo o relato veiculado em sala, era alguém tão íntegro.

Pois é, Calmon acabou sendo uma leitura próxima. De certa forma, muitas das posições que acabei seguindo no direito têm muito do seu modo de pensar e de agir. Quem me conhece sabe de minhas frases de efeito lançadas ao estilo de Calmon. Já até afirmei que um dia confeccionarei camisas com as frases "eu quero é regra" e "eu odeio neoCons" (alusão ao neoconstitucionalismo). Sei que a oração "eu odeio" é muito forte, mas é muito da fala de Calmon e irei usar, no final de minha exposição, um texto de Calmon que tece considerações duras sobre o neoconstitucionalismo. Nisso estou bem acompanhado.

Eu, particularmente, sou um positivista kelseniano, mas a verve de Calmon sempre foi muito nítida em minha formação.

Tive a chance de ouvir Calmon, em Recife, acho que num evento referido por Pedro Henrique Nogueira na abertura deste Congresso. Foi em 1994. Orador brilhante, levou mais de mil pessoas no Centro de Convenções a aplaudi-lo de pé. Muitos em lágrimas. Lembro de uma alegoria que ele fez que me marcou profundamente. Afirmava, com dedo em riste:

"As elites brasileiras são como os padres da época do descobrimento. Eles rezavam missas voltadas para a Europa.

De costas para o povo. Olhando para a Europa, rendiam homenagem à matriz. Nossa elite faz isso ainda. Dá as costas para o povo e rende homenagem à matriz.”

Esse pensamento crítico de Calmon acompanhou e acompanha minha jornada. Tanto é que, sem perceber, muitas vezes, algumas falas minhas acabam reverberando as lições que o homenageado nos legou. Eu me encontro na leitura de Calmon, nos vídeos de seus discursos. Ele é um grande nome do direito brasileiro.

Há um outro fator que me liga a Calmon de Passos. Um dos grandes professores que tive, talvez a grande influência na minha formação como professor de direito processual, foi Francisco Wildo Lacerda Dantas que, infelizmente, recentemente nos deixou. Ele foi orientando de Calmon de Passos.

Fica evidente como minha trajetória, de modo direito e indireto, é permeada pela obra de Calmon de Passos. Ele não me conheceu, mas eu me reconheço em inúmeros de seus traços. Por isso quero prestar essa homenagem a Calmon. Eu não seria quem sou se não fosse Calmon. É importante deixar registrado isso.

Minha exposição terá por objeto analisar um texto de Calmon de Passos denominado "Revisitando o Direito, o poder, a justiça e o processo", publicado pela editora JusPodivm, em 2012. Esse será o objeto de meu diálogo.

\section{Direito como poder}

Para tratar propriamente do tema devo deixar claro que, no pensamento de Calmon, o direito não tem uma independência funcional em relação ao poder. Para ele, direito e poder são faces da mesma moeda. Em suas falas gravadas encontramos expressões como "não, eu não posso começar a falar em direito sem falar de poder". Esse poder é político e, por isso, para ele, toda construção do direito e a ideia de processo partem desse pressuposto necessário.

Calmon de Passos está na esteira de grandes juristas e oradores baianos. Registro, por relevante numa linha muito próxima a Calmon, a figura de João Mangabeira, professor e um dos grandes nomes da política nacional em meados do século XX. Com ele aprendi sua visão de justiça como veículo de mudança, quando deixa claro que não podemos pensar a justiça como simplesmente dar a cada um o que é seu. Afirmava: "se justiça é dar a cada um o que é seu, então dê a fortuna ao rico e a miséria ao 
miserável". ${ }^{2}$ Dessa verve Calmon de Passos é herdeiro. A Bahia formou pensadores fantásticos! João Mangabeira é um que eu queria mencionar.

Mas, voltando à ideia de direito de Calmon, ele deixa claro que direito é poder. Só que esse poder é uma categoria que deve ser modulada através de um procedimento, e a esse procedimento ele chama de democracia. É fantástico como ele irá relacionar de forma direta a construção do Direito com a democracia. Isso é central em sua obra.

Por que Calmon de Passos é processualista? Porque ele pensa o direito como produto de um processo democrático. Eu costumo dizer que eu sou kelseniano porque vejo na Teoria Pura do Direito uma teoria do processo: um processo de produção de normas, principalmente quando Hans Kelsen trata da dinâmica do ordenamento jurídico. ${ }^{3}$ Calmon usa a democracia como esse procedimento, esse processo.

Essa democracia é quem pode transformar o poder em um modelo racional e controlado de regulação da sociedade, que é o direito. Sem esse processo democrático, tem-se a barbárie, o autoritarismo. A democracia se estabelece de modo nítido como um devido processo legal criador do direito.

É interessante notar que Calmon não deixa, ao tratar o direito com poder, de ser processualista, porque, na realidade, a democracia é um processo. Então, quando ela regula, produzindo o direito, ela afirma: "olha, eu regulo com máxima emancipação". ${ }^{4} \mathrm{E}$ acrescenta: "quanto mais emancipação eu tiver nos grupos, menor a necessidade de regulação". ${ }^{5}$ De certa forma, essa ideia de Calmon de que numa democracia deve haver o máximo de emancipação e o mínimo de regulação comunga com o pensamento de Pontes de Miranda no que denomina "redução do quantum despótico", ${ }^{6}$ ou seja, quanto mais se diminui o uso da força, mais condição há para se realizar a igualdade material. Calmon trabalha com esta dupla contingência: "eu tenho de ter igualdade material para ter liberdade". Noutros termos, ele advoga ser necessário diminuir a ideia de conflito e aumentar a ideia de cooperação.

Essa leitura de Calmon me faz lembrar outro autor, que me acompanhou na época da graduação, o filósofo húngaro George Lukács. ${ }^{7}$ Ele trabalha, em sua obra, a ideia de que quanto mais a sociedade for cooperativa, mais ela diminuirá a violência do conflito. Baseia muito de suas ideias no modelo social das primeiras civilizações gregas, que na visão de Aristóteles tinha clara a noção de que o "homem só, ou é um deus ou é uma besta".

Outro ponto interessante, no pensamento de Calmon, é que ele se mostra muito ciente de que o poder não transige, não liberaliza. O poder tem na sua essência, por vocação, oprimir, excluir, desapropriar. Essas são as funções do poder.

Só que esse poder se torna serviço quando é domesticado, controlado pela democracia. Então, o que ocorre? Ele entende o processo como um instrumento apto a capturar essa massa forte que é o poder e torná-lo algo humano. E por que torná-lo humano? Creio que há aí uma influência muito forte de Carlos Cossio ${ }^{9}$ e de outro autor baiano, Machado Neto, seu discípulo. Neles há a percepção existencialista clara de que o homem é "condenado a ser livre", como diria Jean-Paul Sartre ${ }^{10}$, que influencia Cossio, que influencia Machado $\mathrm{Neto}^{11}$. Para ele, o homem está livre das grades dos instintos,

2 MANGAGEIRA, João. Ideias políticas de João Mangabeira. 2. ed. Brasília: Senado Federal, 1987.

3 KELSEN, Hans. Teoria Pura do Direito. Trad. de João Baptista Machado. São Paulo: Martins Fontes, 1994.

4 CALMON DE PASSOS, J. J. Revisitando o direito, o poder, a justiça e o processo. Salvador: Juspodivm, 2012.

5 CALMON DE PASSOS, J.J. Op. cit.

6 PONTES DE MIRANDA, Francisco Cavalcanti. Introdução à sociologia geral. 2. ed. Rio de Janeiro, Forense, 1980.

7 LUKÁCS, Georg. História e consciência de classe. Trad. Rodnei Nascimento. São Paulo: Martins Fontes, 2003.

8 ARISTÓTELES. Política. Trad. Nestor S. Chaves. Rio de Janeiro: Ediouro, s/d.

9 COSSIO, Carlos. La teoría egológica del derecho y el concepto juridico de libertad. Buenos Aires: Editorial Losada, 1944.

10 SARTRE, Jean-Paul. O ser e o nada. Trad. Paulo Perdigão. São Paulo: Vozes, 1997.

11 MACHADO NETO, Antonio Luiz. Fundamentación egológica de la teoria general del derecho. Buenos Aires: Editora Universitaria de Buenos Aires, 1973. 
e para permanecer livre deles, necessita pensar no devir. A necessidade de dar respostas ao devir faz com que sejamos compelidos a estabelecer regulações.

Só que Calmon pensa o direito de forma instrumentalizada, concretizado como linguagem. Isso também é outro ponto que me aproxima dele, já que minha formação, no doutorado e no mestrado, parte da ideia de direito como linguagem. Sou muito mais ligado ao aspecto sintático do que ao pragmático. Para Calmon - e ele está corretíssimo -, a linguagem tem a função descritiva, expressiva e prescritiva, e o direito prescreve.

É no modo prescritivo que o direito se coloca para coagir e não para persuadir. Mais uma vez é nítido o direito como poder, e nisso também fica clara a influência de Ihering, na "Luta pelo Direito". ${ }^{2}$ Isso remonta à formação de Calmon na Casa de Tobias Barreto. Tobias Barreto é sergipano e o grande jurista do século XIX, que, além de um dos grandes nomes da Filosofia do Direito, nomeia a Faculdade de Direito do Recife, onde me doutorei. Foi aí que Calmon se graduou, e essa influência de Ihering é muito forte na Faculdade de Direito de Recife graças a Tobias Barreto.

Essas ideias vão mostrando como Calmon percebe o direito. Para ele, "o direito não está no céu, não está voando, ele está aqui”. ${ }^{13}$ Não se pode deixar o direito fora do contexto histórico-cultural. Ficam aqui registradas algumas das diversas influências que permeiam o pensamento de Calmon, que deita raízes na Escola de Recife e na Escola Baiana, tão bem representada pelo pensamento de Machado Neto e João Mangabeira.

\section{Direito como construção humana}

Para Calmon de Passos, o direito não é dado, mas é processualmente produzido. Esse papel democrático é algo fundamental para que se possa estabelecer o processo e um produto capaz de possibilitar emancipações. Claro que esse processo não é terapia de casal; as contingências existem e, para Calmon, isso é importantíssimo.

Então o processo irá atuar. Quando é que o direito surge? Há, no nosso sistema, um processo constitucional de construção do direito chamado processo eleitoral. Calmon trabalha o processo como uma categoria mais ampla: há o processo eleitoral, o processo legislativo no plano abstrato, o processo de concreção, de materialização, que é o negocial, administrativo, e o judicial. Neste ponto há uma nítida leitura kelseniana de Calmon.

Essa versatilidade de Calmon de Passos impressiona. Mas não confunda versatilidade com uma salada desconexa de pensamentos. Ele é versátil porque consegue traçar um fio condutor entre as diversas vertentes do pensamento sociojurídico e filosófico do direito. Há unidade no pensamento dele. Essa unidade o faz singular e, por isso, original.

A ideia do processo se fixa como uma forma inconteste de minimizar o arbítrio. O processo tem esta função: diminuir esse quantum despótico, principalmente no que se refere à prevalência da maioria. A democracia precisa dinamizar-se e concretizar-se na relação entre o regime da maioria e o freio das garantias fundamentais. É nas garantias fundamentais que a maioria encontra o limite necessário apto a manter a diferença, possibilitando um regime plural.

Por isso o Poder Judiciário deve ser contramajoritário. É algo fundamental para a manutenção de um regime democrático. Sem o respeito às minorias, a democracia perde seu caráter essencial, a capacidade de inserir, no poder, a diferença. Sem a diferença representada e respeitada, a democracia morre. Quando o Poder Judiciário passa a atuar ouvindo o clamor das ruas, ele perde sua função e condena a democracia à sua derrocada.

Outro ponto crucial no pensamento de Calmon sobre a democracia é que ela não é formada por homens livres, senão por organizações capazes de coagir os que representam a sociedade. Essa capacidade de coagir dos grupos é fundamental. Esse jogo democrático deve subordinar interesses,

12 IHERING, Rudolf von. A luta pelo direito. São Paulo: Martin Claret, 2009.

13 CALMON DE PASSOS, J.J. Op. cit. 
competições e certezas. Essas são as condições para que haja democracia. "A democracia pressupõe igualdade material". ${ }^{4}$

A crítica que ele faz às falsas democracias é mordaz. Para ele, ocorre a falsa democracia quando de alguma forma o poder tende a impedir o resultado. Aqui paro para citar Calmon, no seu trabalho Revisitando o Direito:

"Diversamente ocorre no regime autoritário ou falsamente democrático. Formalmente dito democrático, mas substancialmente organizado de maneira autoritária. No qual o aparato do poder tem a capacidade de impedir a ocorrência de certos resultados políticos através de controle sobre a sociedade não apenas no ex ante, mas também ex post, exercendo controle subjetivo sobre as decisões." ${ }^{15}$

É tão atual essa fala de Calmon. Lendo isso, eu me recordo da famigerada operação "Lava-Jato", que foi uma construção direcionada para impedir o livre processo democrático. Prevendo eventos como esse, chegou a afirmar: "ainda bem que vou estar morto, porque na realidade isso vai acontecer". ${ }^{16} \mathrm{Eu}$ costumo usar no meu dia a dia a expressão "eu acho é pouco, porque eu avisei".

Então, o que acontece? Você tem uma condução de um poder, não o Poder Judiciário, mas um poder que vai direcionar o processo legislativo, o processo de escolha. Repito, quando eu tenho um direcionamento para impedir o resultado democrático, isso redunda numa falsa democracia.

Fica claro, no pensamento de Calmon, que há no Brasil um espectro, um simulacro de democracia. Isso tem uma causa. Mais uma vez ele, em sua literalidade: "o Brasil não tem classe, e sim estamentos". ${ }^{17}$ Ele está tão certo que chega a dar medo. E por que isso? Enquanto a Europa estava banhada em sangue pós-Revolução Francesa, de matriz liberal, a família real portuguesa vem ao Brasil para manter o Estado absoluto. Essa situação acaba sendo uma marca indelével em nossa sociedade.

Calmon é realmente brilhante. Perceber o mover histórico que tanto condiciona nossa sociedade faz-me colocá-lo, de certa forma, ao lado de grandes teóricos da humanidade como Maquiavel ou Marx. Maquiavel que talvez tenha sido, nos últimos séculos, o primeiro autor que usou a história como método. Calmon faz isso, e ele faz de forma muito atual e sutil ao analisar a evolução do capitalismo em relação à própria democracia.

Na democracia, é preciso perder e vencer. Então, perdi o jogo. Isso não acaba, continua. Amanhã venço, continua. Esse mover é algo necessário na democracia.

A democracia permeia o processo constitucional de criação do direito, com idas e vindas. Para Calmon, o que caracteriza a origem democrática do direito é a garantia de liberdade individual dos grupos, a existência de órgão de controle no exercício no poder (ele defende que todo poder tem de ser controlado pelo povo e pelo Judiciário - e faz isso de modo invulgar). Deixa claro que é necessário limitar a atuação do poder econômico para proteger as pessoas da coisificação. Para isso, afirma, faz-se necessário destinar a economia não para o lucro, mas para o atendimento das necessidades humanas.

Em suas lapidares palavras: "a economia existe para defender e possibilitar que as pessoas tenham uma vida melhor, e não lucro". Ele é bastante incisivo em relação a isso. Provavelmente hoje ele seria chamado de comunista, segundo o discurso simplificador em voga.

Calmon não merecia estar nesse mundo, neste período.

O econômico é relevante, mas não é natural, é humano. As leis da economia não são leis matemáticas como alguns querem fazer crer, mas são históricas, sociais e geográficas. E cumprem funções. Elas não são categorias metafísicas. Não são transcendentes. São imanentes.

Sei que muitos não irão concordar, mas vamos deixar claro, o meu olhar acaba estabelecendo os pressupostos do que vejo. E meu olhar não é isento. Ele tem lado. Sou de esquerda. No entanto, isso não torna minha análise dispensável. Todos partimos de algum lugar. Como venho deixando claro na

14 CALMON DE PASSOS, J.J. Op. cit.

15 CALMON DE PASSOS, J.J. Op. cit.

16 CALMON DE PASSOS, J.J. Op. cit.

17 CALMON DE PASSOS, J.J. Op. cit. 
minha exposição, percebe-se nitidamente que Calmon também tem seu ponto de partida; ele faz com que seu olhar seja singular, permeado pelas diversidades.

\section{Críticas ao neoconstitucionalismo - em defesa da legalidade}

Em sua obra, destaca-se também uma análise atualizada do direito em face das diversas doutrinas que tratam da argumentação. Essa preocupação de Calmon tem por cerne o ato de aplicar o direito, como objeto do processo de concreção das normas abstratas veiculadas do processo legiferante.

Nesse ponto, Calmon nutre-se das obras de Atienza $^{18}$ e de Alexy ${ }^{19}$ e tece críticas severas ao chamado neoconstitucionalismo.

Caminho para o final de minha fala.

Essa obra, ${ }^{20}$ lançada em 2012, é de publicação póstuma, como já registrado. Nela se afirma que: “o discurso antipositivista afasta a supremacia da lei e da Constituição". ${ }^{21}$ Para ele, o neoconstitucionalismo nega o positivismo, repudia a separação positivação de direito e moral, além de partir da ideia de que a Constituição conteria todos os valores éticos, cabendo aos aplicadores encontrá-los.

No pensamento de Calmon, o neoconstitucionalista vê a diferença entre a Constituição e a lei para além do campo formal. Haveria uma diferença axiológica. A lei não teria essa carga valorativa que a Constituição possui. A Constituição, sim, seria o receptáculo da carga moral. O problema é: de quem?

Esse campo axiológico não é formado por uma moral positiva, porque se fosse, ela se submeteria ao direito. Não se submete. Para o neoconstitucionalista, essa moral estaria acima do direito, como algo que o transcende. É um jusnaturalismo extremamente não racional, mas simplista. E aí eu sempre me pego com uma frase atribuída a Bernard Shaw: "para todo problema complexo existe uma solução simples e errada”.

Então, o que acontece? A lei cede à Constituição. A lei, que é a expressão da democracia, fica no plano secundário. Disso se pode inferir: se a lei cede aos ditos valores transcendentes da Constituição, ela serve para quê? Para nada. É um mero apêndice, usado como argumento quando atende aos anseios do aplicador ou solenemente descartado quando não condiz com sua vontade. Isso tem sido visto de modo frequente. Não se estar a afirmar que a Constituição deve obediência à lei. Não. O que se afirma é que no regime democrático a lei completa a Constituição. Ela não consegue regular o mundo da vida sozinha.

Ao descartar a lei, faz tábula rasa da Constituição. Um continente sem conteúdo. Por isso em um regime democrático, a lei importa. Ela realiza a Constituição tendo por ponto de partida os valores partilhados pela sociedade.

Calmon vai além em sua análise. Se eu sigo a Constituição, quem garante a Constituição? Ora, afirma, quem garante a Constituição em nosso modelo é o Supremo. E quem é o Supremo? Calmon responde: no Brasil, "temos Supremos, porque cada juiz singular se arvora como juiz constitucional" ${ }^{2}$.

A consequência disso é que a Constituição acaba sendo o que eles dizem. Não temos um deus, mas uma miríade. Calmon faz uma relação com o jusnaturalismo religioso, com um adendo: "não é mais um deus uno e trino que diz o direito, mas deuses galáxias". ${ }^{23}$ Não teria pensado em uma expressão melhor.

18 ATIENZA, Manuel. As razões do direito. $2^{a}$ ed. Rio de Janeiro: Forense, 2014

19 ALEXY, Robert. Teoria da argumentação jurídica. $5^{\mathbf{a}}$ ed., Trad. Zilda H. S. Silva. Rio de Janeiro: 2019.

20 CALMON DE PASSOS, J.J. Op. cit.

21 CALMON DE PASSOS, J.J. Op. cit.

22 CALMON DE PASSOS, J.J. Op. cit.

23 CALMON DE PASSOS, J.J. Op. cit. 
Calmon será contra essa ruptura. Para ele a lei importa. É a regra voltada para a realidade e, por isso, é importantíssima. A Constituição é apenas uma lei que, do ponto de vista sintático, está em uma relação de sobreposição, mas ela não consegue construir todo o ordenamento jurídico.

Neste ponto, sou contrário, por exemplo, ao pensamento do tributarista Geraldo Ataliba, que chega a afirmar que para ele basta a Constituição e que não é necessário ir ao Código Tributário Nacional para resolver problemas de tributação. Ele precisa sim! Como ele vai construir, por exemplo, o fato gerador do imposto de renda? As especificidades estão na lei, a lei importa, ela é expressão do princípio da legalidade.

Tem-se visto muito isso. Há muitos processualistas administrativistas, civilistas etc. que intentam colocar a legalidade com categoria de segunda classe. Fogem da lei. Apesar de a Constituição consagrar a legalidade, valem-se de termos vagos como juridicidade ou ordem jurídica para fugir do rigor técnico que o termo lei veicula.

Por essas e outras razões tenho afirmado que sou refratário a essa categoria denominada princípio, muito usada para concretizar arbitrariedade. Aqui me valho do que Carlos Ari Sundfeld afirma de forma ácida: "princípio é preguiça”. ${ }^{24}$ É preguiça mesmo. Usado como argumento, ou melhor, como desculpa, já que argumento é juízo utilizado para uma conclusão. Desculpa não é argumento, já que quem pede desculpa tem culpa. Na verdade, quem se vale de princípio, geralmente, não justifica, mas lança mão de uma desculpa para a sua arbitrariedade.

Calmon neste ponto vaticina: decidir sem fundamentar é uma violência absurda contra o Estado de Direito, pois não presta contas ao poder democrático. ${ }^{25}$ Nisso, Calmon de Passos se aproxima nitidamente de Michele Taruffo. ${ }^{26}$

Agora me lembrei de Caetano Veloso, outro baiano brilhante, que canta: "você diz a verdade, a verdade é seu dom de iludir". No direito, muitas "verdades" são ditas com base nessas concepções neoconstitucionalistas e como fontes de ilusão. Neste contexto, Calmon tem uma frase fantástica, que até usei nas redes sociais para divulgar o presente evento:

“O neoconstitucionalismo é uma ideologia antidemocrática e despolitizadora na medida em que propõe o direito como fonte de libertação e o Judiciário como agente de transformação.”27

É isso que é o neoconstitucionalismo. Por que é assim? Porque no momento que eu retiro do poder democrático, que representa, no caso, o Parlamento, a sua produção e digo que ela nada é e quem vale é o Judiciário através do seu aparato, através da sua aplicação constitucional, eu tenho um problema.

Para terminar, vou me valer da ideia da legislação simbólica, que Calmon usa na sua obra. Uma nítida alusão ao trabalho de Marcelo $\mathrm{Neves}^{28}$, bem presente nos traços de Calmon de Passos. A crítica dele é precisa: "olha, a Constituição Federal está cheia de direitos, é ingovernável". ${ }^{29}$ Mas porque Calmon dizia isso? Não porque fosse contra os direitos, pelo contrário, ele diz que "o problema é você usar a legislação para engessar a sociedade no seu movimento para melhorias”. Quando você concede você não dá, você tolhe. ${ }^{30}$

24 SUNDFELD, Carlos Ari. "Princípio é preguiça?” in Direito administrativo para céticos. 2. ed. São Paulo: Malheiros, 2014 .

25 CALMON DE PASSOS, J.J. Op. cit.

26 TARUFFO, Michele. A motivação da sentença civil. Trad. Daniel Mitidiero, Rafael Abreu e Vitor de Paula Ramos. São Paulo: Marcial Pons, 2015.

27 CALMON DE PASSOS, J.J. Op. cit.

28 NEVES, Marcelo. A constitucionalização simbólica. 3a ed. São Paulo: Martins Fontes, 2011.

29 CALMON DE PASSOS, J.J. Op. cit.

30 CALMON DE PASSOS, J.J. Op. cit. 
Esse tolhimento vem sob a forma de concessões. Calmon mostra que nossa ordem jurídica não reflete nosso povo, mas maquia a realidade com certo tipo de civilidade que não irá ser concedido, com o intuito de manter privilégios. ${ }^{31}$

Quando eu olho a questão da legislação simbólica, e vou aqui pegar um exemplo para terminar mesmo, do então senador baiano Antônio Carlos Magalhães, que queria aumentar o salário para o equivalente a cem dólares, na época do governo Fernando Henrique Cardoso, FHC fez o seguinte: "olha, eu não vou aumentar, mas autorizo os Estados-membros a fazê-lo". Fez então aprovar uma Lei Complementar. Noutros termos: "vocês não querem dar o aumento do salário-mínimo? Deem vocês, senhores governadores”. O que aconteceu? Ele usou essa lei não para aumentar o pacto federativo, dar maior distribuição das competências... Não. Ele colocou a lei para acabar a discussão.

Muitas vezes, quando eu confiro direitos, não estou resolvendo o problema; estou colocando aquilo para acabar a discussão e diminuir o chamado "jogo democrático".

Calmon de Passos é brilhante, é fantástico. Calmon me emociona. Eu fico muito feliz de estar falando em Calmon e agradeço o convite que me foi feito, mais uma vez. Professora Mayara Carvalho, obrigado pela paciência, eu sei que acabei passando do tempo. Passo agora para você a palavra. Muito obrigado.

\section{Palavras finais}

Gostaria de parabenizar as excelentes falas do Professor Paulo Modesto, da Professora Cláudia Albagli, do Professor Marcus Seixas e do Professor Emílio Viana. Parabéns, Professora Mayara Carvalho, pela excelente condução.

Quando me deparei com os textos de Calmon, vi que ele trabalhava com a teoria da linguagem, com o direito como linguagem, como texto. Ele tem uma preocupação muito interessante com o campo da aplicação, ou seja, como essa linguagem prescritiva irá alterar o modo de agir das pessoas.

Vi que nele há uma influência muito grande de Machado Neto e, na mesma esteira, de Carlos Cossio. Então, como o direito prescreve, a intenção dele é sair do plano da abstração para o plano da concreção. Para fazer isso, ele se vale das teorias da argumentação para, dentro do embate democrático, no caso, no processo, transformar a abstração, prevista na lei, em concreção.

Ele afirma que o positivismo clássico acabou dando ênfase primordialmente à questão do direito enquanto plano sintático da validade. Esqueceu do aspecto fático. Ele percebe que há a necessidade de o direito refletir no caso e, assim, alterar a realidade. Aqui me valho da lição de Lourival Vilanova: "o direito não coincide, ele incide.” ${ }^{22}$ Incide para alterar. Se coincidisse, não faria sentido.

Agora me lembrei de um conto de Jorge Luís Borges, "O fazedor - do rigor em ciência". ${ }^{33}$ Neste conto se colhe que, se o mapa corresponder ao local mapeado, ele perde sentido. O mapa é um redutor de complexidade.

Para chegar da abstração à concreção, preciso traçar um caminho que é feito através de discurso argumentativo, controlado mediante o processo.

Qual é o fim? O fim não importa. O Professor Paulo Modesto foi fantástico em relação a isso. O que importa é ter o texto como ponto de partida e fixar o procedimento. A chegada é o produto desse processo. Só o amanhã dirá.

Calmon cumpriu com maestria seu legado e deixou para nós o dever de continuar sua jornada. Mais uma vez, muito obrigado.

\footnotetext{
31 CALMON DE PASSOS, J.J. Op. cit.

32 VILANOVA, Lourival. Escritos jurídicos e filosóficos. São Paulo: Axis Mvndi - IBET, 2003.

33 BORGES, Jorges Luis. O Fazedor - Do rigor em Ciência. Trad. Rolando Roque da Silva. 4. ed. Bertrand Brasil, 


\section{Referências}

ALEXY, Robert. Teoria da argumentação jurídica. 5ª ed., Trad. Zilda H. S. Silva. Rio de Janeiro: 2019. ARISTÓTELES. Política. Trad. Nestor S. Chaves. Rio de Janeiro: Ediouro, s/d.

ATIENZA, Manuel. As razões do direito. 2a ed. Rio de Janeiro: Forense, 2014.

BORGES, Jorges Luis. O Fazedor - Do rigor em Ciência. Trad. Rolando Roque da Silva. 4 ed. Bertrand Brasil, 1987.

CALMON DE PASSOS, J. J. Revisitando o direito, o poder, a justiça e o processo. Salvador: Juspodizm, 2012.

COSSIO, Carlos. La teoría egológica del derecho y el concepto juridico de libertad. Buenos Aires: Editorial Losada, 1944.

IHERING, Rudolf von. A luta pelo direito. São Paulo: Martin Claret, 2009.

KELSEN, Hans. Teoria Pura do Direito. Trad. de João Baptista Machado. São Paulo: Martins Fontes, 1994.

LUKÁCS, Georg. História e consciência de classe. Trad. Rodnei Nascimento. São Paulo: Martins Fontes, 2003.

MACHADO NETO, Antonio Luiz. Fundamentación egológica de la teoria general del derecho. Buenos Aires: Editora Universitaria de Buenos Aires, 1973.

MANGABEIRA, João. Ideias políticas de João Mangabeira. 2ª ed. Brasília: Senado Federal, 1987.

NEVES, Marcelo. A constitucionalização simbólica. 3ª ed. São Paulo: Martins Fontes, 2011.

PONTES DE MIRANDA, Francisco Cavalcanti. Introdução à sociologia geral. 2. ed. Rio de Janeiro, Forense, 1980.

SARTRE, Jean-Paul. O ser e o nada. Trad. Paulo Perdigão. São Paulo: Vozes, 1997.

SUNDFELD, Carlos Ari. "Princípio é preguiça?" in Direito administrativo para céticos. 2ª ed. São Paulo: Malheiros, 2014.

TARUFFO, Michele. A motivação da sentença civil. Trad. Daniel Mitidiero, Rafael Abreu e Vitor de Paula Ramos. São Paulo: Marcial Pons, 2015.

VILANOVA, Lourival. Escritos jurídicos e filosóficos. São Paulo: Axis Mvndi - IBET. 2003 